\title{
DIÁLOGOS POSSÍVEIS: ENTRE A AUTOPOIESIS E AS TECNOLOGIAS DA INTELIGÊNCIA
}

\author{
KÁtia Morosov Alonso* \\ Danilo GaRCIA DA SILVA** \\ MARIA CRISTINA DA SILVEIRA*** \\ MABEL MOREIRA STROBEL ${ }^{* * * *}$
}

\begin{abstract}
Não há seres "mais" adaptados, pois a autopoiese, conservação da organização, congruência operacional, é um requisito para a existência, para a vida. Lógica proscritiva: tudo o que não é proibido é permitido. Cada ser é produto e produtor da evolução.
\end{abstract}

(Maturana \& Varela, 2001, p. 127)

\begin{abstract}
RESUMO: O trabalho tem por objetivo discutir aproximações entre os pensamentos de Maturana e Varela (2001) sobre sistemas autopoiéticos em diálogo com Lévy (2010), trazendo à cena as denominadas Tecnologias da Inteligência. Nesta perspectiva, pretende-se fomentar uma conversação entre conceitos propostos pelos autores, de modo que seja relevada compreensão sobre as tecnologias digitais da informação e comunicação. Isso como espaço profícuo para o desenvolvimento de ambiências de aprendizagens que congreguem e exprimam possibilidades de interação e experiências inovadoras. Igualmente, propõe-se problematizações considerando a transcendência das tecnologias antes mencionadas, tendo em vista o conceito de psicotecnologias calcadas na ideia de extensão não apenas de corpos, como também de mentes humanas, e as possíveis tendências no campo educacional ao se empreender análise nesse sentido.
\end{abstract}

Palavras-chave: Autopoiese. Tecnologia da inteligência. Tecnologias digitais da informação e comunicação. Psicotecnologias.

\footnotetext{
* Doutora em Educação e professora adjunta do Programa de Pós-Graduação em Educação da Universidade Federal de Mato Grosso (UFMT). E-mail: katia.ufmt@gmail.com

* Doutorando em Educação na UFMT e membro do grupo de pesquisa Laboratório de Estudos sobre Tecnologias da Informação e Comunicação do Instituto de Educação da mesma Universidade. E-mail: danilogsilvas@gmail.com

*** Doutoranda em Educação na UFMT e docente da Faculdade de Enfermagem da mesma Universidade. E-mail: mariacristina.silveira@yahoo.com.br

**** Doutoranda em Educação na UFMT e secretária de Educação do município de Barão de Melgaço (MT).E-mail: mbstrobel@hotmail.com
} 


\section{Possible DiAlogues: BetWEen AUTOPOIESIS}

\section{AND INTELLIGENCE TECHNOLOGIES}

ABSTRACT: This paper aims to discuss similarities between the thoughts of Maturana and Varela (2001) on autopoietic systems in a dialogue with Lévy (2010), bringing in the so-called Intelligence Technologies. In this perspective, it is intended to foster a conversation between concepts proposed by the authors in order to unveil their understandings on Digital Technologies of Information and Communication. This would be as a fruitful space for the development of learning ambiances associating and expressing possibilities of interaction and innovative experiences. It also proposes considering problematizations on overcoming the aforementioned technologies, from the concept of psycho-technologies point of view, grounded on the idea of the extension not only of bodies, but of human minds and the possible trends in the educational field when undertaking analysis in this direction.

Key words: Autoipoiese. Intelligence Technology. Digital technologies of information and communication. Psycho-technologies.

\section{DiAlogues POSSIBles: ENTRE L'AUTOPOIESIS ET LES TECHNOLOGIES DE L'INTELLIGENCE}

RÉSUMÉ: Cet article vise à discuter des ressemblances entre la pensée de Maturana et Varela (2001) sur les systèmes autopoiétiques dans un dialogue avec Lévy (2010), faisant surgir ce qu'on appelle les Technologies de l'Intelligence. Dans cette perspective, il vise à susciter une conversation entre les concepts proposés par les auteurs afind' approfondir la compréhension sur les Technologies Numériques de l'Information et de la Communication. Ceci comme un espace fructueux pour le développementd' ambiances d'apprentissages quiassocient et expriment des possibilités d'interaction et d'expériences innovantes. En outre, on propose de considérer des problématisations considérant la transcendance des technologies mentionnées ci-dessus, vu le concept des psychotechnologies copié de l'idée d'extension non seulement des corps, mais aussi des esprits humains et des tendances posibles dans le domaine de l'éducation quando nentreprend l'analyse dans ce sens.

Mots-clés: Autoipoiese. Technologie de l'intelligence. Technologies numériques de l'information et de la communication. Psychotechnologies.

\section{Para começo da conversa}

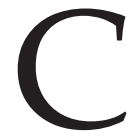

om o presente texto são propostas reflexões que considerem elementos fundamentais para um diálogo entre Maturana e Varela (2001) sobre sistemas autopoiéticos, e os de Lévy (2010) quanto aos conceitos de tecnologias da inteligência e ecologia cognitiva. Relacioná-los significa ampliar determinadas compreensões sobre o uso das tecnologias digitais da informação e comunicação (TDIC), potencializadas em realidade virtual em uma perspectiva mais ampla e densa, como exposta por Kerckhove (2009). Para além de extensões do corpo - a ideia de extensões da psicologia humana -, as TDIC, por sua plasticidade, ao proporcionarem interação 
e interatividade, conformariam não só outras e novas expressões de nós mesmos, mas "cunhagens" profundas nos modos pelos quais as culturas são organizadas atualmente. Quais seriam implicações disso no modo pelo qual pensamos, nos relacionamos e aprendemos? Responder a esta questão seria, então, uma das chaves para se entender a vinculação entre processos do ensinar e aprender, por exemplo, originados nos dias de hoje na e pela convergência de mídias, que geram o que se denomina "cultura digital", extensão e mescla de nosso modo de pensar e agir, traduzida no que produzimos e atualizamos, e que é chamado por Lévy (1999a) de "cibercultura". É impossível no espaço de um artigo explorar e/ou esgotar todas as implicações ou denotações dos processos e dinâmicas advindas de tal movimento. A ideia é a de indagar aqui sobre as possibilidades de um diálogo, que parece profícuo, para compreensão do uso das TDIC implicadas agora em uma "mente coletiva" (Kerckhove, 2009). Ao trazer as concepções de Maturana e Varela (2001) e as de Lévy (2010), é possível compreender as tramas que subjazem à inserção das TDIC nos cotidianos e o modo pela qual atuam nas maneiras de pensar contemporâneas.

\section{Sobre os elementos essenciais da conversa}

Com a compreensão de que as TDIC consistem em recursos informáticos integrados aos de telecomunicações, que vêm se desenvolvendo desde o fim da Segunda Guerra Mundial, tem-se a perspectiva de que estas tecnologias fundem/acoplam os potenciais inerentes a cada um desses meios eletrônicos - recursos informáticos e de telecomunicação -, para ampliar as probabilidades de serem expandidas pelo uso que fazemos delas.

A evolução das TDIC, impulsionada pelo avanço da rede mundial de computadores, propiciou o desenvolvimento de uma sociedade permeada pelas tecnologias digitais, que se transformaram, na definição de Kerckhove (2009), em "eletrotecnologias". Em sua perspectiva, haveria uma alteração importante, posta por essa nova realidade eletrônica. Se, em um primeiro momento, a causa de simultaneidades, como apontado por McLuhan (1995), se dava por conta do advento da eletricidade, agora elas seriam consequência do uso das TDIC, percebidas não mais como extensão dos corpos, mas das mentes humanas.

Observa-se que tais tecnologias poderiam proporcionar simulação, virtualidade, acessibilidade, abundância e diversidade de informações que são constantemente atualizadas. Para Lévy (1999a, p. 16), “a atualização aparece como a resolução de um problema ou uma solução". A atualização seria a característica da possibilidade, em que a realização de um possível está na significância atribuída pela enunciação de uma informação. Atualizar seria, dessa forma, a solução encontrada pelo sujeito a partir da relação de significância estabelecida com a informação, no contexto da "cibercultura". 
Maturana e Varela (2001), pela perspectiva biológica em que suas propostas se assentam, defendem que os fenômenos humanos seriam também biológicos, justamente pelo "adentramento" do biológico ao social, orientando o desenvolvimento do sistema nervoso. A evolução da estrutura biológica e das experiências humanas resultaria, então, no fenômeno do conhecimento. Assim, os autores definem o fenômeno do conhecer como "uma ação efetiva, ou seja, uma efetividade operacional no domínio de existência do ser vivo. (...) ação que permita um ser vivo continuar sua existência em um determinado meio ao fazer surgir o seu mundo" (Maturana \& Varela, 2001, p. 35-36). “Viver é conhecer (viver é ação efetiva no existir como ser vivo)" (p. 194).

As linhas gerais dos pensamentos anteriormente indicados implicam, portanto, compreender as raízes mesmas de como se organizaria o conhecimento, tendo como pressupostos, além da ideia de que a vida já se configuraria por e com essa finalidade, uma base social estabelecida nas relações/interações/interatividades vislumbradas pelo uso das TDIC. Em ambos os casos, a linguagem aparece como fator fundante, fazendo do humano algo peculiar. Também em ambos, o interagir e o relacionar são reconfigurados, intuindo outras formas de conceber os conhecimentos.

O conceito de "autopoiese" (biologia cognitiva) focaliza o realizar/fazer dos seres vivos. ${ }^{1}$ Aqui se observam dois domínios de realização (operação) que se entrecruzam em nosso viver: o domínio fisiológico do organismo, em sua dinâmica estrutural interna (de que faz parte o sistema nervoso, como um sistema fechado), em que ocorre a autopoiese; e o domínio do viver na dinâmica relacional. Estes domínios permitiriam entender os fenômenos que sucedem em cada um, em particular, e entre nós seres humanos: a linguagem, as emoções e a cognição.

Fisiologicamente, o ser vivo é (um sistema vivo) uma rede de moléculas que interagem entre si, de modo que, por meio de tais interações, produziriam o mesmo tipo de moléculas da rede que as produziu, constituindo uma unidade em rede (Maturana \& Varela, op. cit.).

Com esta compreensão, as mudanças teriam origem em transformações contínuas, configurando o ser histórico. Contudo, como um sistema determinado estruturalmente, o ser vivo somente viveria seu presente na dinâmica da fisiologia. Logo, viveria assim o ser humano, enquanto ser vivo biológico. Por outro lado, ao viver por meio da linguagem, abre-se para ele um "presente" no qual há expressão de um passado e futuro que decorre, logicamente, da ideia de uma história de mudanças estruturais subjacentes à biologia dos seres vivos. Nas mudanças então é que as coerências estruturais seriam vivenciadas, ou seja, antes de terem um sentido pelo suposto conteúdo do que é dito, têm sentido pela história de coerências estruturais a que pertencem. 
Na dinâmica relacional, o ser vivo é autônomo, ao passo que "nas interações entre os seres vivos e o meio ambiente dentro da congruência estrutural, as perturbações ${ }^{2}$ do ambiente não determinam o que acontece com o ser vivo; ao contrário, é a estrutura do ser vivo que determinará o que deverá ocorrer com ele" (idem, ibid., p. 108).

Importante frisar que a compreensão de autonomia não é aquela da liberdade completa, mas de descentração, implicando considerar o outro, exigindo responsabilidade nas ações e decisões. Esta distinção evidencia outra perspectiva de aprender, baseada nas relações sociais definidas pela cooperação e reciprocidade, absolutamente como um discurso ausentado de realidade. Dessa maneira, ao se pronunciar sobre o conhecimento necessário, deve-se atentar para o viver: "Se a vida é um processo de conhecimento, os seres vivos constroem esse conhecimento não a partir de uma atitude passiva e sim pela interação. Aprendem vivendo e vivem aprendendo" (ibid., p. 12).

A vida seria entendida, portanto, como processo de conhecimento. Se o objetivo for o de compreendê-la, é imprescindível pensar em como os seres vivos conhecem o mundo (Maturana \& Varela, 2001). Para os dois teóricos, conhecer seria viver, e viver seria, pois, conhecer. O ser humano é definido, então, como sistema autopoiético, constituído como em rede na qual os componentes engendrariam o sistema circular que os produz. O ser e o fazer de um sistema vivo seriam inseparáveis, não existindo separação entre produtor e produto em uma unidade autopoiética.

A autopoiese tem sua etimologia no grego, significando autoprodução. Segundo Maturana e Varela (op. cit.), somos seres vivos constituídos de unidades autopoiéticas e inseridos num contexto histórico, passíveis, portanto, de modificações, justamente pela condição de sujeitos históricos.

Um sistema autopoiético seria, ao mesmo tempo, produtor e produto. A autonomia, como propriedade dos seres vivos, ${ }^{3}$ traria consigo a ideia de que as modificações de um sistema aconteceriam à medida que procurassem conservar sua própria organização. A noção de autonomia estaria vinculada à de dependência, ou interdependência, inseparáveis da de auto-organização. Sendo assim, conhecer seria "uma ação efetiva, ou seja, uma efetividade operacional no domínio de existência do ser vivo" (op. cit.., p. 35). Para os autores, o pensar teria quatros componentes:

I. Fenômeno a explicar: ação efetiva do ser vivo em seu meio ambiente;

II. Hipótese explicativa: organização autônoma do ser vivo. Deriva filogenética e ontogenética, com conservação da adaptação (acoplamento estrutural);

III. Dedução de outros fenômenos: coordenação comportamental nas interações recorrentes entre seres vivos e coordenação comportamental recursiva sobre a coordenação comportamental; 
IV. Observações adicionais: fenômenos sociais, domínios linguísticos, linguagem e autoconsciência. (idem, ibid.)

Com isso, o conhecimento ocorreria "toda vez que observamos um comportamento efetivo num contexto assinalado, ou seja, num domínio que definimos como uma pergunta (explícita ou implícita) que formulamos como observadores" (Maturana \& Varela, op. cit., p. 31). Ao mesmo tempo, levando a assumir "atitude permanente de vigília, contra a tentação da certeza, a reconhecer que nossa certeza não são provas de verdade" (idem, ibid., p. 267).

O conhecimento é concebido, então, como ato cognitivo, implicando entendimento sobre sistema nervoso e caráter sistêmico da célula do organismo (Mariotti, 1999). O sistema nervoso estaria continuamente em mudança, viabilizada pela plasticidade das interações entre os órgãos sensoriais e efetores, mas com a conservação de sua adaptação (Maturana \& Varela, op. cit.).

Tais mudanças Maturana e Varela (op. cit.) chamam de acoplamentos estruturais ou interações que o ser humano estabelece consigo, com o outro e com o meio. Tal processo é tido como fundamental para a capacidade de aprendizagem, ampliando "enormemente as possibilidades de plasticidade estrutural do organismo" (idem, ibid., p. 184).

Partindo dessa afirmação, é possível perceber que a inteligência se configuraria por e em sua plasticidade. Essa é dimensão fundamental para os autores informarem a possibilidade de participação em diferentes domínios de consensualidade, ao passo que possamos nos mover livremente de um domínio consensual a outro, num fluxo de ampliação de um domínio consensual "primeirário".

Ao considerarmos a árvore do conhecimento de Lévy (1999a), percebemos a dimensão sociológica de uso das TDIC. Este autor propôs um sistema composto por um software de cartografia, que permitia aos membros de uma coletividade (escola, grupos comunitários, entre outros) informar o conjunto de suas habilidades, aquilo que eles sabiam e a forma pela qual aprenderam. Assim, pelo intercâmbio de conhecimentos entre pessoas e comunidades, teríamos uma ampla enciclopédia virtual dinâmica. Dessa forma, a árvore de uma comunidade cresceria e se transformaria na medida da evolução das competências da própria comunidade. Em outras palavras, a árvore do conhecimento faria referência ao mundo virtual, fundamentado no conhecimento e nas possibilidades de compartilhamento.

Na perspectiva de Lévy (2010), considerar a compreensão de inteligência em sua plasticidade, ou como capacidade de compartilhar mundos, torna possível mudar o foco da educação. Educar não seria, para ele, "fornecer informações" (apontar objetos) de diversos mundos, mas provocar mudanças estruturais e promover 
transformação subjetiva, por compartilhamento de mundos em que não se mostram paisagens, mas dão-se olhos. Aprender seria, portanto, um movimento de adentrar em um mundo desconhecido pertencente a outro.

Kerckhove (2009) considera que, atualmente, as tecnologias transcendem extensões de nossos corpos, tornaram-se "psicotecnologias" por emularem, estenderem e amplificarem o poder de nossas mentes. Sendo assim, já não se prestariam mais a alterações apenas biológicas/musculares; influenciariam já relações sociais, culturais, econômicas e políticas. Longe da ideia de apropriações ingênuas, o que se teria aqui seriam interações poderosas que, ao reconfigurarem tempos e espaços, admitiriam ressignificações profundas nos modos pelos quais apreendemos o real, como uma interface a exteriorizar consciências. Nesse sentido, a ideia da conectividade, como acesso pessoal ao mundo inteiro, marcada pela interação, faz surgir uma tendência, como propõe o autor, de uma "coletivização psicotecnológica".

Compreendendo, pois, a inteligência em sua plasticidade, ao mesmo tempo trazendo a perspectiva das interações, uma dinâmica particular e dialética, que se estabelece na relação dos sujeitos pelo uso das TDIC, mais que a busca por informação, observa-se a tendência de simbioses no domínio do humano, entendido como capacidade de aprender, ampliada agora pelas TDIC, autorizando outras e novas formas de expressão e do agir. Dessa forma, essas simbioses que ocorrem em níveis e espirais restringiriam ou ampliariam o leque de ações humanas, condicionando e determinando aquisições e apropriações do pensar mediado pela linguagem. Isso implica operações "de um sistema social humano, cujo ponto central é o domínio linguístico gerado por seus componentes e a ampliação das propriedades destes" (Matura $\mathcal{E}$ Varela, 2001, p. 221).

Ao invocar Lévy (2010), a linguagem aparece em suas diversas formas de expressão (verbal e não verbal) e no processo de leitura, consistindo produção menos vertical, mais igual, de novos textos; transita-se de um lado a outro nos espaços de produção de sentidos, instituindo-se sistemas de referência, referenciando-os com base no domínio de compreensão dos sujeitos. Este domínio de compreensão consiste nas interconexões estabelecidas para atribuição de sentidos e significados.

Tal reconfiguração não possuiria uma lógica de começo-meio-fim. Desobedeceria, como propõe Lévy (1999b), a qualquer instrução, tomando rumos transversais e muitas vezes ignorados. Daí a produção de novas obras, dobraduras e interconexões desconhecidas, podendo emergir outras complexidades semânticas. Nos domínios linguísticos, as possíveis interações realizadas pelos humanos, atreladas às técnicas do pensar, linguagem e técnica, contribuiriam para fabricar e modular o tempo (Lévy, 2010).

A tecnologia, na forma de pensar, é tratada pelo mesmo autor como "tecnologias da inteligência, que são apenas condições de possibilidade, dispositivos 
suscetíveis de serem interpretados, desviados ou negligenciados" (idem, ibid., p. 97). A oralidade, a escrita, a impressão, o computador são tecnologias como devir na forma de pensar através dos tempos.

No (re)pensar o tempo histórico da sociedade, das relações sociais e culturais vivenciadas pelo ser humano, residiria a possibilidade de se compreender as organizações sociais, incluindo "todas as técnicas e todas as conexões com o ecossistema físico-biológico que fazem viver" (ibid., p. 77). A presença e a ausência de técnicas fundamentais de comunicação permitiriam, nessa visão, classificar as culturas das sociedades.

De acordo com Lévy (op. cit., p. 77), “os elementos técnicos que condicionam as formas de pensamento ou as temporalidades na sociedade" poderiam ser separados, cronologicamente, em dois tempos: oralidade primária (o papel da palavra) e oralidade secundária (relacionada ao estatuto da palavra, que é complementar à escrita). Ao advogar o argumento de que as técnicas transformadas em tecnologias fariam advir formas diferenciadas de produção do conhecer, pela organização de outras e novas ecologias cognitivas, Lévy (2010) imprime caráter dinâmico e de reconstruções históricas e culturais implicadas naquilo que ele denomina como tecnologias da inteligência. Estas trariam contribuições efetivas "nas derivações das fundações culturais que comandam nossa apreensão do real" (idem, ibid., p. 10).

Haveria, na perspectiva de Lévy (2010), uma reciprocidade no uso dado por nós aos dispositivos técnicos convertidos em máquinas, que alterariam, dinâmica e dialeticamente, as formas pelas quais se processaria o conhecer. As máquinas como produção humana

(...) contribuem para formar e estruturar o funcionamento das sociedades e as aptidões das pessoas, elas muitas vezes efetuam um trabalho que poderia ser feito por pessoas como você e eu. Os dispositivos técnicos são realmente atores por completo em uma coletividade que já não podemos dizer puramente humana, mas cuja fronteira está em permanente redefinição. A ecologia cognitiva é o estudo das dimensões técnicas e coletivas da cognição. (Idem, ibid., p. 139)

É importante destacar que essas tecnologias intelectuais perpassariam a memória humana com implicações emocionais extremamente sensíveis, no tocante aos processos elaborativos, intensificando a criação de novas codificações, representações, bem como da linguagem. Daí o debate sobre essas formas de aquisição. Mais do que nunca, a dimensão cultural, fundada no ciberespaço, constitui e implica a criação e recriação coletiva do saber, realizando e desenvolvendo uma inteligência artificial.

Para Kerckhove (2009), se a linguagem foi uma das primeiras tecnologias humanas, por meio dela é que se iniciaria o processo da informação, tornando-se substância da inteligência humana. 
A ideia, portanto, de que essas criações - e, por consequência, suas indispensáveis internalizações, no sentido proposto por Vygotsky (1991) - são frequentes, penetrando os domínios do conhecer, faz despontar o imperativo de que sejam expressas possibilidades de compreensões e alternativas que provoquem também uma nova organização do processo educativo, por exemplo. Nesse sentido, o conhecer, por sua base biológica intrinsecamente fundida aos processos sociais, gestaria uma inteligência plástica, justamente pelos movimentos e dinâmicas advindos disso; daí que, por tal característica, a associação humanos/tecnologias, especialmente com as TDIC, implicaria outra ecologia cognitiva, com irreversíveis consequências sobre o modo pelo qual a cultura é organizada. Haveria aqui uma tríade - inteligência plástica, associação humanos/tecnologias e ecologia cognitiva - importante de ser constituída no sentido de se intuir, aí sim, entendimentos sobre uma alternativa possível de organização dos processos de formação.

\section{De conversas que se entrelaçam}

Com base no que foi exposto, com o entendimento da plasticidade da inteligência e do pensamento humano, exteriorizados na e pela linguagem, surgiria agora o domínio de uma nova conformação dela, como proposto por Lévy (2010): o hipertexto. ${ }^{4}$ Isto romperia com a linearidade da leitura e do discurso, fazendo admitir elaborações de um conhecimento individual, cuja "fabricação", em decorrência de sermos ao mesmo tempo produtores e produtos dele, engendraria uma dada ecologia cognitiva. É crível então o paralelo a ser estabelecido sobre a compreensão das redes neurais como suporte para elaboração de um conhecimento individual, fomentado pelas interações e interrelações com as diferentes formas de tecnologias da inteligência, ensejando diferentes modos de aquisições e transformações do conhecer, pelo caráter plástico da maneira humana de pensar anteriormente referido.

As TDIC e suas possibilidades conectivas e interativas não operariam a substituição do pensamento humano, ainda que tenham proporcionado à mente humana importantes capacidades de expansão, alterando a relação estabelecida com o conhecimento e com o conhecer; consentiria surgir outras estruturas de redes associativas e esquemas. Isso como decorrência posta pela capacidade de as TDIC, tornadas em realidade virtual, expandirem as conexões da inteligência dos sujeitos distribuídos nesse novo contexto cibercultural.

As TDIC, compreendendo seu potencial na interface com a internet, comportam uma nova trama de conexões, caracterizadas também pela ausência de começo e fim em si mesmos ou de pontos definidos, nos quais cada vez mais a ideia de fluxo e fluidez faz emergir espaços de convivência e de relações. Estas tecnologias autorizariam viver em interações recorrentes, de maneira a também expandir o conceito de 
comunidade. Nesse sentido, e considerando o campo educacional, pensar a invenção de novos espaços de aprendizagem seria um primeiro passo rumo a uma forma que inspira e determina nossas vidas. O desafio para o aprender se assentaria agora, parafraseando Lévy (2010), em aprender a viver num mundo sem chão, mundo este que não é um lugar, é lugar em si mesmo, mundo virtual.

A constituição das redes neurais, com base nas infinitas possibilidades de associações e operações mentais, poderia ser chamada, de acordo com Lévy (op. cit.), de conexões hipertextuais. Considerando as atividades comunicativas em suas formas mais amplas, o estabelecimento de associações mentais significativas estaria atrelado aos contextos em que são produzidas, como contextos designativos "da configuração de ativação de uma grande rede semântica em um dado momento" (Lévy, op. cit., p. 23). Assim,

(...) a imensa rede associativa que constitui nosso universo mental encontra-se em metamorfose permanente. As reorganizações podem ser temporárias e superficiais, quando, por exemplo, desviamos momentaneamente o núcleo de nossa atenção para audição de um discurso, ou profundas e permanentes como nos casos em que dizemos que "a vida" ou "uma longa experiência" nos ensinaram alguma coisa. (Idem, ibid., p. 24)

Sob esta ótica e apropriando-se dos conceitos apresentados, presume-se a aprendizagem como uma maneira hipertextual do conhecer, pois à medida que se submetesse a perturbações do exterior, desencadearia na mente (hipertextual) uma série de relações e conexões com o já conhecido, liberando neste movimento a construção/constituição do próprio conhecimento. Para Lévy (op. cit.), a função da comunicação não se restringiria apenas à transmissão de informação, mas seria sinônimo de ação, em que o contexto compartilhado entre os sujeitos conectados seria, a todo o momento, redefinido, recomposto, rearticulado e transformado.

Nos cenários desafiadores de possibilidades do aprender com as TDIC e com as dimensões tempo e espaço alteradas, a educação, por sua formalidade, é instada a atender demandas emergentes da sociedade atual. Um aprender que implicaria agir, interagir e conviver, de modo que cada sujeito, como "nós" em rede (no sentido de atualizá-la), estivesse em constante extensão, como produtor e emissor de novas informações imprevisíveis, reorganizando e reorganizando-se por conta própria, como parte de uma conectividade global.

Entendendo que as TDIC se convertem em espaços de convivência potencializados e que as relações aí estabelecidas desencadeariam aprendizagens, a rede digital oportunizaria, por meio do trabalho colaborativo e cooperativo, um caminhar significativo para a "formação" em seu caráter mais formal, de sujeitos. Isso como espaço potencializador de agentes atuando em rede, num ambiente pulsante, "um organismo vivo", incidindo, como anunciado por Kerckhove (2009), em alterações 
nas formas pelas quais nos relacionamos, sejam elas sociais, políticas, econômicas ou educacionais.

Na dinâmica relacional, como proposta por Maturana e Varela (2001), as TDIC seriam promotoras de relações que flexionariam elementos como espaço e tempo, como consequência da internet. Por meio dela, haveria a criação de dobraduras e reentrâncias espaço/temporais para a consecução de um sujeito mais "global". Para Kerckhove (op. cit.), contudo, local e global não se configuram como opostos, mas como complementaridades, reconhecendo que as telecomunicações, como as que temos atualmente, impuseram situações bastante contraditórias:

(...) comunidades humanas que vivem em diferentes velocidades, com níveis muito diferentes de experiência social são lançadas de encontro umas às outras sem aviso nem mediação [...] Quanto mais noção temos da globalidade mais ficamos conscientes das unidades locais, e mais nos protegemos. É esse o paradoxo da aldeia global. O hiperlocal é o complemento inevitável do hiperglobal. (Kerckhove, op. cit., p. 178-194)

Nesse contexto, algumas características das TDIC são incorporadas, projetando o perfil daqueles que com elas convivem. Este "convivente" deixa de ser um simples participante do processo comunicacional; completa-se agora como autor cuja intervenção, por meio de operações dialógicas associadas em emissão e recepção, não mais como atos antagônicos, mas complementares e em cocriação comunicacional, alteraria o conteúdo das mensagens, manipulando-as e modificando-as.

O conceito de autopoiese apoia a compreensão de que os sistemas trabalham produzindo a si mesmos, em domínios de interação com outras unidades, ocupando funções ora como "organizadores" (coletivo-individual), ora como "autores" (individual-coletivo), isso como configuração da identidade de um sistema em um âmbito que produz sentido a quem o observa. Por estrutura são definidas entidades específicas que operam no "desenho" da organização.

Com isso, entende-se que um sistema de trabalho fundamentado nas TDIC permite aproximações com a ideia de autopoiese, por sua autonomia na e para a produção de conhecimento, em dependência com o aprender, estabelecendo-se, agora, numa relação de coletividade, de modo que individual e coletivo se encontrem, experimentando-se. Significa que cada cenário, com suas interações particulares, seria posto como um microssistema autopoiético, compreendendo-o como autoprodução de relações intersubjetivas que constituem o aprender, mas entremeado por um geral que se manifesta por meio da linguagem (escrita, iconográfica/ imagética, sonoras, etc.), expressa nos e pelos conteúdos/mensagens e pelo "intertextuar" entre os sujeitos. Esses sujeitos-autores-aprendentes autoproduziriam e organizariam toda uma amplitude de um sistema autopoiético. 
Ao se observar e refletir sobre o uso das TDIC, notadamente a constituição de redes por meio delas, são passíveis de reconhecimento algumas de suas características: a troca individual, como essencial para se denotar o processo de autonomia e cooperação; o conviver, como expansão de si mesmo. O conhecimento, como resultado desses adentramentos que convergem para a cooperação e colaboração, manteria uma função organizadora, como um ecossistema colaborativo interdependente. Tal sistema seria conformado, sem dúvida, por componentes técnicos e pelo conjunto de elementos físicos, biológicos e humanos. É esse conjunto maior que justifica a existência do novo e daquilo que Kerckhove (2009) denomina "eletrotecnologias". É este entendimento que faz implicar, então, a aprendizagem, como rede, na lógica da autopoiese em que, simultaneamente, se realizam produtos e produtores do conhecimento.

A ideia é a de que os elementos autopoiéticos, em sua dinâmica, vão evidenciando processos cognitivos enquanto aprendizagem, apoiados na e pela interação com o outro (interindividual) e com o próprio objeto de conhecimento. As contribuições desses interagentes denotam um movimento de autoria e de construção de conhecimento, numa perspectiva participativa nas trocas efetuadas com os outros sujeitos.

Na perspectiva do conhecer, a interação é um dos principais pontos-chave (a relação, por exemplo, seria outro), determinante para o processo da aprendizagem, ao contextualizar vivências para a realidade de cada um dos sujeitos que poderiam, então, ser compartilhadas. As emoções reforçariam as associações, fomentando a convivência para se aprender vivendo e viver aprendendo (Maturana \& Varela, 2001; Lévy, 2010). As informações e mensagens trocadas entre os sujeitos orientariam mudanças de rumo, interações e novos links, conformando outros caminhos e temas de interesse para conversação.

Em linhas gerais, o conhecer e o apropriar-se do sistema humano estariam na vivência, experienciação/simulação postas como trocas/intercâmbios. As trocas recíprocas de ação do sujeito com o objeto de conhecimento ocorreriam como ação intelectual sobre o objeto, retirando dele qualidades que, por meio da ação e coordenação daquilo que faz (age), o sujeito lhe deposita.

Tendo em vista os assuntos expostos envolvendo os elementos constitutivos das ideias de Maturana e Varela (2001) - autopoiese - e de Lévy (2010) - tecnologias da inteligência e ecologia cognitiva -, considera-se que a experiência (como viver biológico e social) não seria algo exclusivo do campo científico, como contrário à empiria, mas, sim, algo pertencente à vida cotidiana, como movimento, sem desconsiderar outras releituras e interpretações sobre esse mesmo tema. De todo modo, o termo experiência é tomado aqui na perspectiva trazida por Maturana e Varela (op. cit.): como não isolada. As experiências atestariam um espaço relacional constituído 
pelas ambiências, ou pelas possibilidades de convivências que os seres humanos vivenciam cotidianamente. Essa acepção também foi visualizada por Lévy (op. cit.) ao compreender as competências e habilidades (savoir-faire) que os indivíduos sociais aditam por meio das relações socioculturais.

Com relação ao campo educativo, busca-se aclarar conceitos que poderiam suportar experimentações que congregassem, então, probabilidades inscritas no entendimento das dinâmicas e movimentos das autopoieses; e naquilo que se tem discutido como tecnologias da inteligência e ecologia cognitiva como forma de adentrar o escolar, em uma proposta que evidencie as oscilações, fluxos e a circulação de uma nova ordem cultural, como afirmado por Kerckhove (2009). Mais que prescrições ou a imposição pura e simples da entrada de artefatos técnicos na escola (em seus vários níveis), valeria a pena introduzir pausa para se pensar/refletir sobre aquilo que, pouco a pouco, vislumbramos como extensões eletrônicas dos sentimentos humanos, fazendo despontar um desconhecido, urgente de ser decifrado.

\section{Para continuar a conversa}

Com base no exposto, mais do que nunca, vivemos o imperativo de que não bastaria derrubar os "muros" da escola, em sua cultura organizacional, apenas. Fica como convite a reflexão sobre o sentido de subversão de determinada ordem há tempos estabelecida, como apontado por Lévy (2010). Nos últimos anos, problematizações e propostas sobre a formação de professores, seja ela inicial ou continuada, têm fomentado algumas "saídas" para o "uso pedagógico", como denominado por várias iniciativas governamentais, das TDIC nas escolas. O maior problema de tais iniciativas tem a ver, sobretudo, com o pensamento, ainda reducionista, de que bastaria trabalhar algumas competências/habilidades técnicas para que estas tecnologias fossem mais bem aproveitadas no cotidiano dos estabelecimentos escolares. Compreender, de fato, as implicações que o uso intensificado delas apresenta, é, sem duvida, elemento crucial para se empreender fazeres que subsidiassem, aí sim, outra maneira de organizar o ambiente escolar com as TDIC.

Com a plasticidade que marca o processo do conhecer, por outro lado, a plasticidade do próprio pensamento agora expandido pelo virtual determina apropriações, em primeiro lugar, que não são simples, em razão da complexidade que envolve tais produções; e, segundo, transforma efetivamente as culturas por conta das novas relações que são gestadas, tendo por consequência extensões que fundem outras "peles culturais" (Kerckhove, 2009). Não se trata de negar os outros empreendimentos humanos: econômicos, políticos e sociais, mas de apontar para o compromisso de que sejam expostas algumas das naturezas de processos que envolvem alterações significativas no conhecer/aprender. 
O que se expressa, no presente texto, é uma maneira de (re)pensar possibilidades sobre a temática, para que sejam considerados princípios que fariam perceber a ligação de extrema intimidade entre nós humanos com as TDIC, no momento em que se começa perceber a potencialidade dos processos comunicacionais possíveis de serem instaurados por meio delas, gerando conhecimentos e expandindo os sentidos mesmos de nossa existência.

\section{Notas}

1. Para este texto, limitou-se a compreensão de ser vivo como ser humano.

2. Ao se referirem sobre "perturbação" Maturana e Varela (2001) não especificam as transformações passíveis de ocorrência. Seriam, pois, como o "disparar de gatilhos", como um efeito a ser definido pela estrutura do ser vivo.

3. Os seres vivos seriam máquinas que se distinguiriam de outras por sua capacidade de se autoreproduzir. (cf. Maturana, 2007)

4. Para Lévy, o hipertexto é um conjunto de nós ligados por conexões. É um documento digital composto por diferentes blocos de informações interconectadas. Essas informações são amarradas por meio de elos associativos, os links. Os itens de informação não são ligados linearmente, em nós, de modo reticular. Através dessas estruturas interativas, o leitor percorre a trama textual de uma forma única, pessoal. O hipertexto informatizado é, portanto, uma rede de textos superpostos que permite ao usuário passar de um ponto a outro sem interromper o fluxo comunicativo.

\section{Referências}

KERCKHOVE, D. A pele da cultura: investigando a nova realidade eletrônica. São Paulo: Annablume, 2009.

LÉVY, P. Cibercultura. São Paulo: Editora 34, 1999a.

LÉVY, P. O que é o virtual? 3. ed. São Paulo: Editora 34, 1999b.

LÉVY, P. As tecnologias da inteligência: o futuro do pensamento na era da informática. 2. ed. São Paulo: Editora 34, 2010.

MCLUHAN, M. Os meios de comunicação como extensões do homem. Trad. Décio Pignatari. 10. ed. São Paulo: Cultrix, 1995.

MARIOTTI, H. Autopoiese, cultura e sociedade. 1999. Disponível em: <http://www. geocities.com/pluriversu/autopoies.html>. Acesso em: 2 maio 2012.

MATURANA, H.R.; VARELA, F.J. A árvore do conhecimento: as bases biológicas da compreensão humana. Trad. de Humberto Mariotti e Lia Diskin. 6. ed. São Paulo: Palas Athena, 2001. 288p.

MATURANA, H. Um problema de desejo: depoimento 5 ago. 2007. Antroposmoderno. 
Entrevista concedida a Omar Sarrás Jadue. Disponível em: <http://www.florindomundo.com/pdf/conhecimento/09maturana.pdf $>$. Acesso em: 2 maio 2012.

VYGOTSKY, L.S. A formação social da mente: o desenvolvimento dos processos psicológicos superiores. São Paulo: Martins Fontes. 1991.

Recebido em 26 de junho de 2012.

Aprovado em 26 de outubro de 2012. 